\title{
Unmanned aircraft system measurements of the atmospheric boundary layer over Terra Nova Bay, Antarctica
}

\author{
S. L. Knuth ${ }^{1}$, J. J. Cassano ${ }^{1}$, J. A. Maslanik $^{2}$, P. D. Herrmann ${ }^{3}$, P. A. Kernebone ${ }^{3}$, R. I. Crocker ${ }^{2}$, and \\ N. J. $\operatorname{Logan}^{3}$ \\ ${ }^{1}$ Cooperative Institute for Research in Environmental Sciences and Department of Atmospheric and \\ Oceanic Sciences, University of Colorado, Boulder, Colorado, USA \\ ${ }^{2}$ Department of Aerospace Engineering Sciences, University of Colorado, Boulder, Colorado, USA \\ ${ }^{3}$ Aerosonde ${ }^{\circledR}$ Pty. Ltd, Melbourne, Australia \\ Correspondence to: J. J. Cassano (john.cassano@colorado.edu)
}

Received: 19 October 2012 - Published in Earth Syst. Sci. Data Discuss.: 13 November 2012

Revised: 25 January 2013 - Accepted: 25 January 2013 - Published: 18 February 2013

\begin{abstract}
In September 2009, a series of long-range unmanned aircraft system (UAS) flights collected basic atmospheric data over the Terra Nova Bay polynya in Antarctica. Air temperature, wind, pressure, relative humidity, radiation, skin temperature, GPS, and operational aircraft data were collected and quality controlled for scientific use. The data have been submitted to the United States Antarctic Program Data Coordination Center (USAP-DCC) for free access (doi:10.1594/USAP/0739464).
\end{abstract}

\section{Introduction}

Within the Terra Nova Bay (TNB) region of Antarctica, strong air-sea interactions occur during the winter months due to the presence of a persistent latent heat polynya generated largely due to strong downslope winds originating from the interior of the continent (Kurtz and Bromwich, 1983; Ciappa et al., 2012). These air-sea interactions are strongest during the winter months as the downslope and katabatic winds bring cold, dry air in contact with the relatively warmer and moister air overlying the polynya. Typical ice conditions in the region consist of open water immediately offshore, with areas of pancake and pack ice further away from the coast (Fig. 1). However, ice conditions within TNB can vary greatly depending the strength of the prevailing winds, where calm winds can result in pack ice being present up to the coastal edge. Understanding the impact of the interaction between the cold, dry continental air and the open water of the polynya on atmospheric storms, energy transfer to and from the atmosphere, and the changing properties of oceanic water are important for furthering our knowledge of both local and large-scale meteorological, glaciological, and oceanographic changes.

In September 2009, a series of unmanned aircraft system (UAS) flights were undertaken over the TNB polynya to measure changes in the atmospheric layer overlying the polynya (Cassano et al., 2010). The UAS used for these flights were built and designed by Aerosonde ${ }^{\circledR}$ and collected atmospheric measurements (air temperature, skin temperature, $\mathrm{u}$ - and v-components of the wind, atmospheric pressure, relative humidity, and shortwave and longwave radiation), geo-reference data (latitude, longitude, altitude), and aircraft-specific information (roll, pitch, yaw, aircraft height, and ground speed). A Canon SX110 IS digital camera was mounted on the UAS to collect images of the sea surface and ice state in the polynya. The data were recorded on board the aircraft using data loggers and memory cards and also telemetered back to the field team in real time (except for digital photographs) during the flights using Iridium satellite communication (when over the horizon) or $900-\mathrm{MHz}$ radio (when within line of sight). 


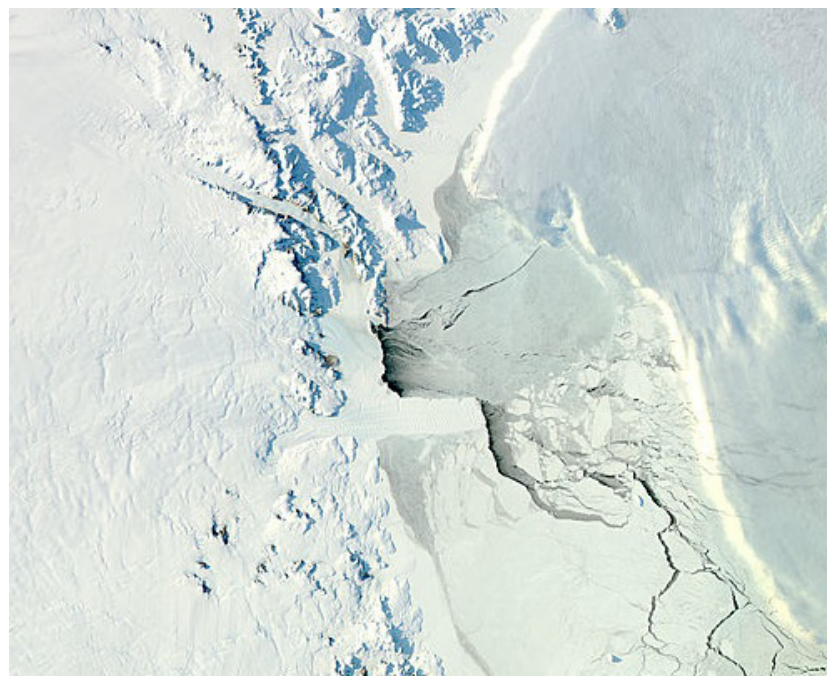

Figure 1. One kilometer Aqua True Color satellite image from 24 September 2009. The Drygalski Ice Tongue, located in the center of the image, extends approximately $50 \mathrm{~km}$ from the coastal edge into the sea. North is at the top of the image. Data collected from the website of the National Aeronautics and Space Administration (NASA) at http://lance-modis.eosdis.nasa.gov/imagery/ subsets/?mosaic $=$ Antarctica.

The purpose of these flights was to document the downstream evolution of the boundary layer over Terra Nova Bay and to study air-sea interactions in the winter months over the Terra Nova Bay polynya (Figs. 1 and 2). The meteorological data collected by the UAS are sufficient to allow us to document the downstream evolution of the temperature, humidity, winds, and the boundary layer over the polynya. The data collected are also sufficient to allow us to estimate the turbulent sensible heat, latent heat, and momentum fluxes as well as to estimate all of the terms in the horizontal momentum equation. The method for estimating these terms from the UAS data will be described in separate papers that are currently in preparation. Turbulent flux instrumentation was not carried during the flights due to weight restrictions and to keep the instrumentation simple and robust.

Various data loggers on the UAS collected the data with varying sampling rates. As part of the quality control process, the data were rigorously checked for false or spurious data as well as streamlined into cohesive sampling rates. The final dataset is provided to the general public in two different formats at a sampling rate of ten seconds. A description of the UAS and flights, the quality control process, and the publically available dataset is provided below.

\section{UAS description and flights}

During September 2009, the Aerosonde ${ }^{\circledR}$ UAS flew sixteen flights - eight flying north from the Pegasus ice runway near McMurdo Station to TNB (Fig. 3), six flights flown near Pe-

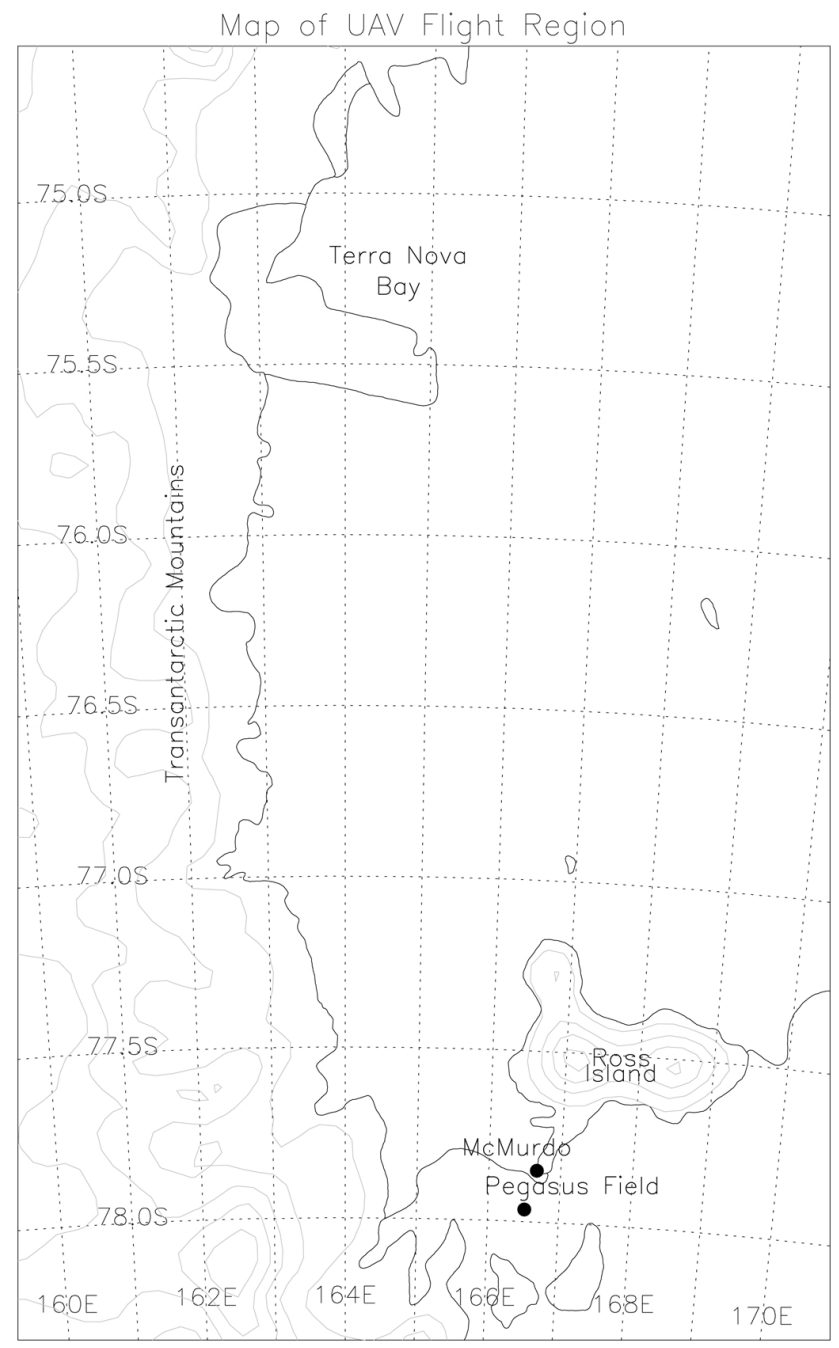

Figure 2. Map of the entire UAS flight region, from Pegasus Runway to Terra Nova Bay.

gasus (Fig. 4), and two unsuccessful flight missions (Fig. 5). The six flights near Pegasus were largely test flights used to ensure proper aircraft instrument operations, while the eight flights to TNB were science flights (Table 1).

The following describes the standard flight pattern for the science flights to TNB. During the flights to TNB, the aircraft followed the Transantarctic coast north to TNB and telemetered data back to the field team at Pegasus Runway via Iridium satellite. Once the aircraft did a complete south to north transect of TNB near the coast, the mission scientist used the telemetered meteorological data to locate the position of strongest winds across TNB. Based on this, a revised set of waypoints and altitudes were then uploaded in real time to the Aerosonde's autopilot, and the UAS then flew parallel to the strongest winds (as determined from the telemetered data stream) across TNB (Fig. 6). Finding the area of strongest winds was important for meeting the scientific goals of the project, which included estimating the largest air-sea fluxes 
14 September 2009 AV 214 Flight Map

21 September 2009 AV 214 Flight Map

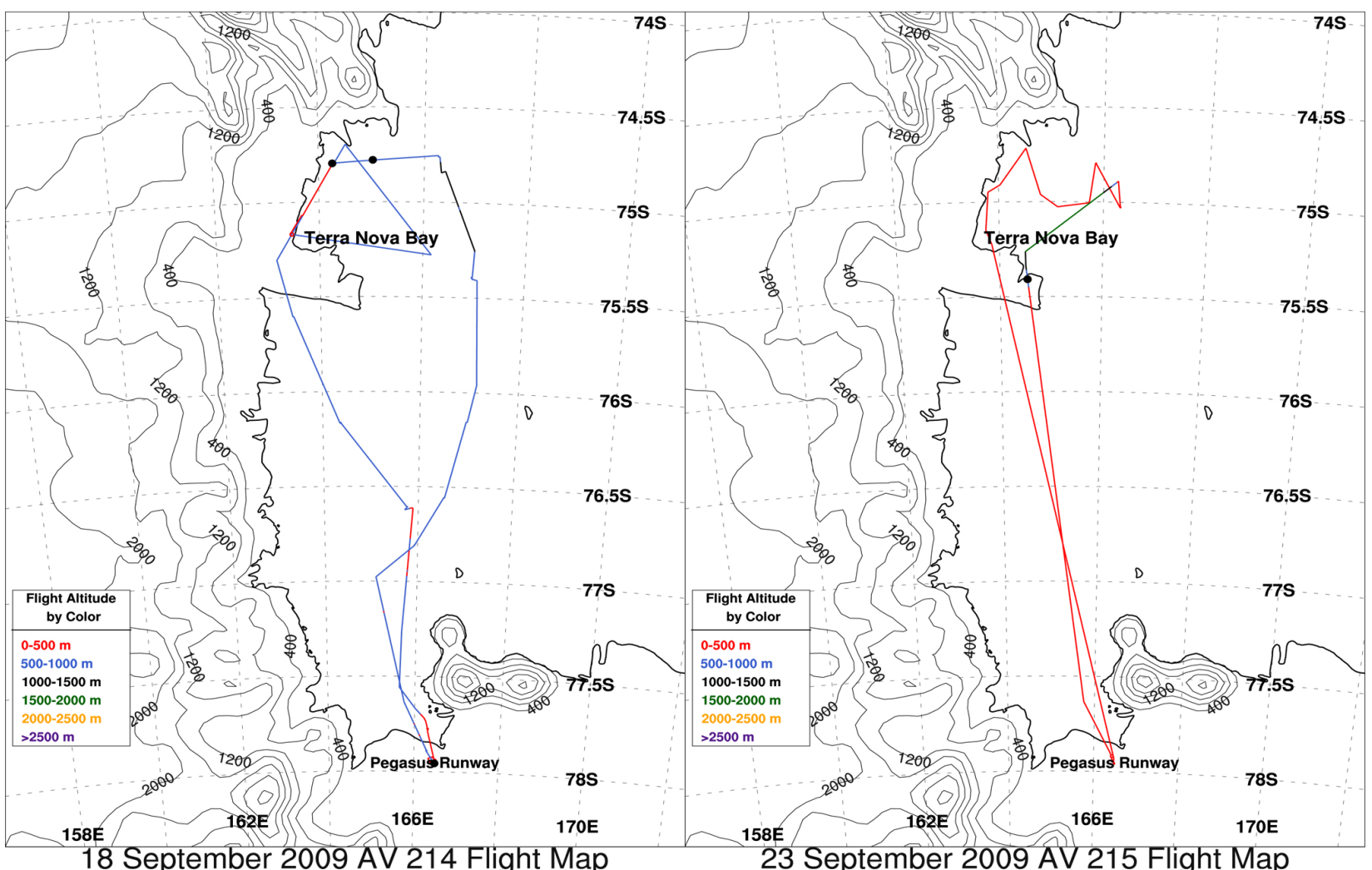

18 September 2009 AV 214 Flight Map

23 September 2009 AV 215 Flight Map

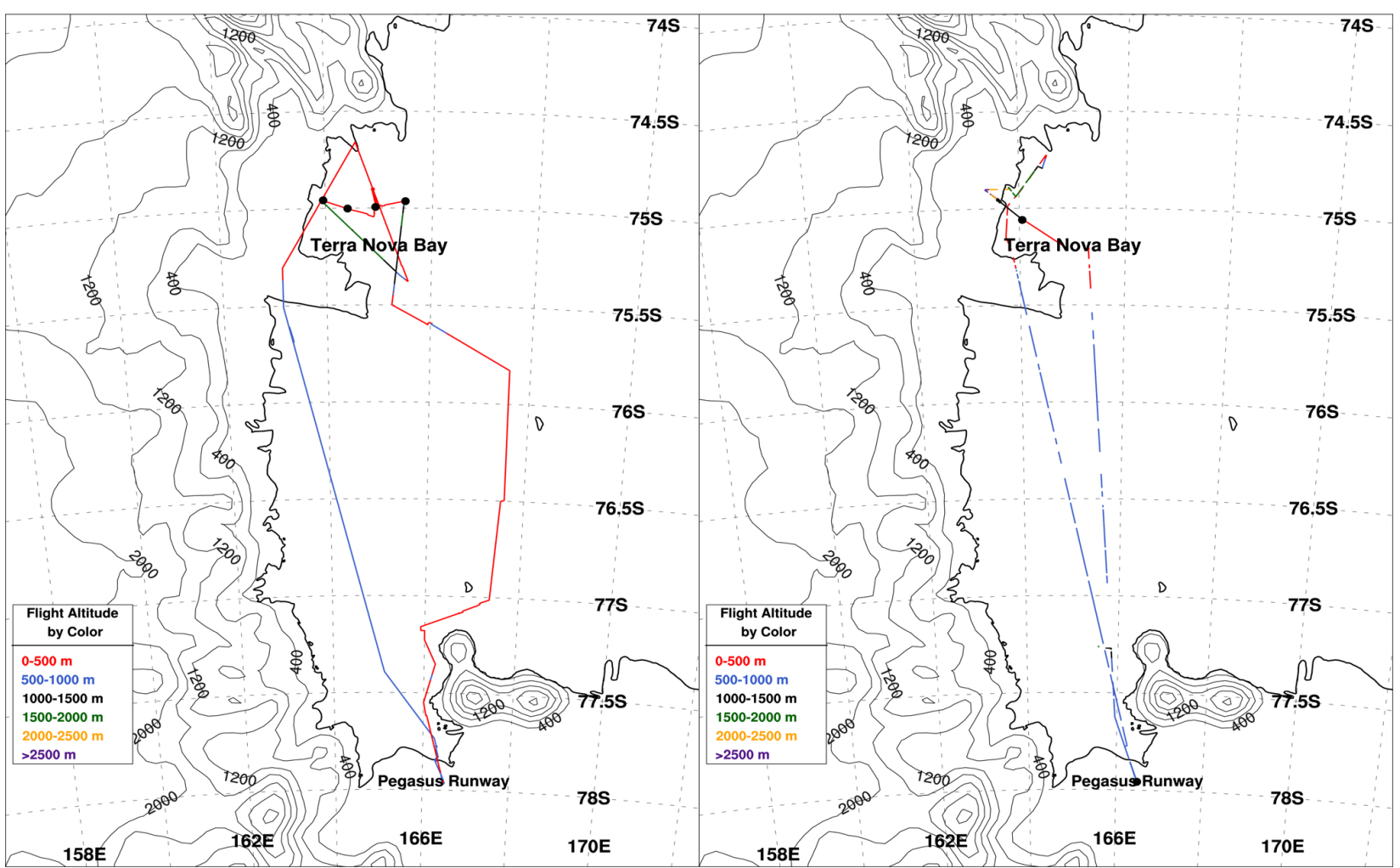

Figure 3. Flight path for the eight science flights from Pegasus Runway to Terra Nova Bay. Gaps in the flight path indicate a lack of data. Profile locations are marked with a black dot. Flight altitude is indicated by the color scale shown in each panel. Topographical contours are in meters. 


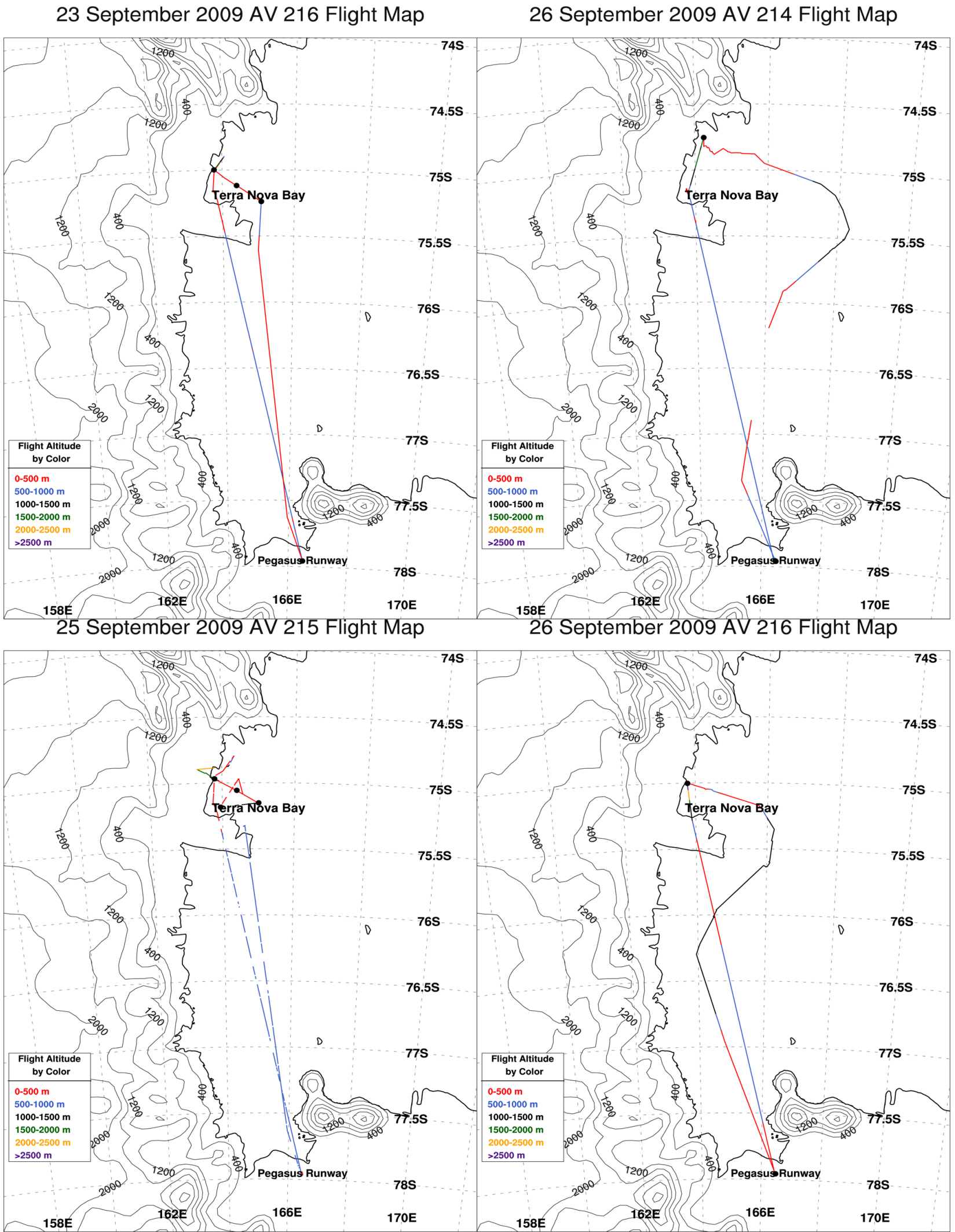

Figure 3. Continued. 

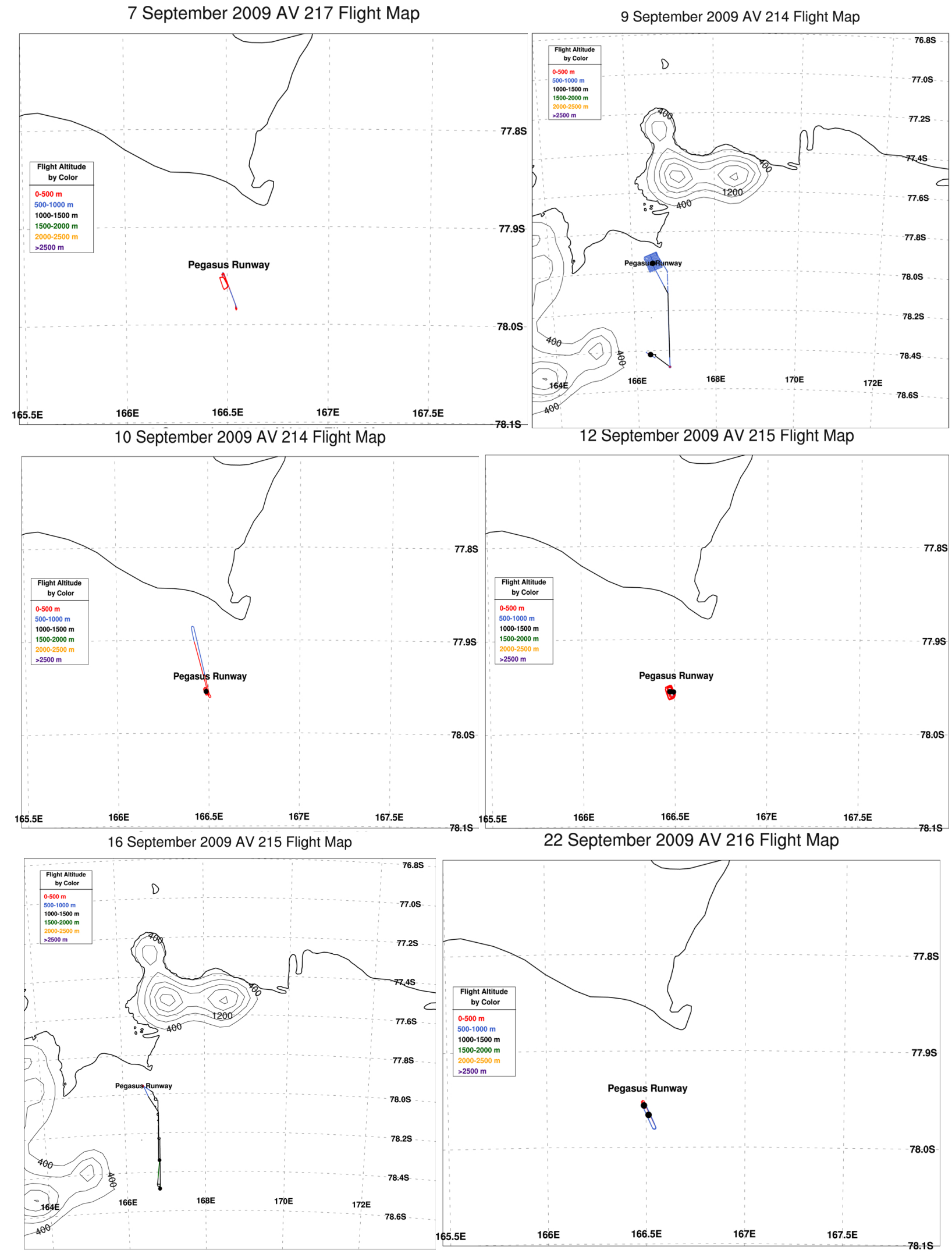

Figure 4. Flight path for the six local flights near Pegasus Runway. Gaps in the flight path indicate a lack of data. Profile locations are marked with a black dot. Flight altitude is indicated by the color scale shown in each panel. Topographical contours are in meters. 
over the polynya. As air-sea fluxes are (in part) controlled by wind strength, flights within the area of strongest winds provided the data to calculate the largest fluxes within TNB. This flight strategy also documented the downstream evolution of the fluxes when moving from stronger to weaker winds within the jet.

Along this flight path the UAS performed soundings of the atmosphere at several locations. Figure 7 shows examples of three specific humidity profiles taken along the flight path measured by a UAS on 23 September. Each of these profiles consisted of a spiral ascent, a spiral descent, or both. The top altitude of each spiral ascent or descent pattern varied by flight but was chosen to ensure that the entire depth of the boundary layer was sampled. The local flights near Pegasus Field had no regular and consistent pattern between flights (Fig. 4).

The Aerosonde ${ }^{\circledR}$ UAS (Maslanik et al., 2002; Curry et al., 2004; Inoue and Curry, 2004; Inoue et al., 2008) are designed and built in Australia for commercial use, and these flights required a field team of four to fly. Extensive, previous use in the Arctic demonstrated the potential of the Aerosonde system for polar operations (Curry et al., 2004). The UAS used for the TNB missions in 2009 had a wingspan of $3 \mathrm{~m}$, a weight of $15 \mathrm{~kg}$, and a payload capacity of $2-5 \mathrm{~kg}$. The aircraft had a range of over $1000 \mathrm{~km}$ and an endurance of $18 \mathrm{~h}$, and were flown between approximately 150- and 3000-m altitude during the flights. Typically, the downwind flight transects were flown at an approximately constant altitude between 150 and $250 \mathrm{~m}$ (Figs. 3 to 5). The UAS were not flown at a lower altitude due to concerns about the presence of tall icebergs in the area as well as inaccuracies in the GPS altitude data. The planes were manually pilot-controlled at takeoff and landing and operated in full autonomous mode during most of the flight, with real-time telemetry to the ground station and pilot in command. The pilots had the ability to take over controls or alter the flight plan at any time.

The instruments on board the UAS include both the instruments internal to the UAS as well as additional meteorological instruments added specifically for the 2009 flights and built in Australia for commercial use, and for these flights required a field team of four to fly. The internal UAS flight management system, including the autopilot, GPS navigational system, flight sensors, communications, and payload interfaces, were Piccolo components developed by Cloud Cap Technologies, Inc. Data from the Piccolo system were available on all flights and were telemetered back in real time. The meteorological instruments added to all of the UAS included pressure data (Vaisala PTB110), skin temperature (Everest Interscience, Inc. Everest 3800ZL), air temperature and relative humidity (Vaisala HMM213), and a nadirviewing digital camera (Canon Powershot SX110 IS). The $\mathrm{u}$ - and v-components of the wind were calculated during aircraft maneuvers. The autopilot navigation system contains a Kalman filter, which estimates the wind vector continuously
8 September 2009 AV 217 Flight Map

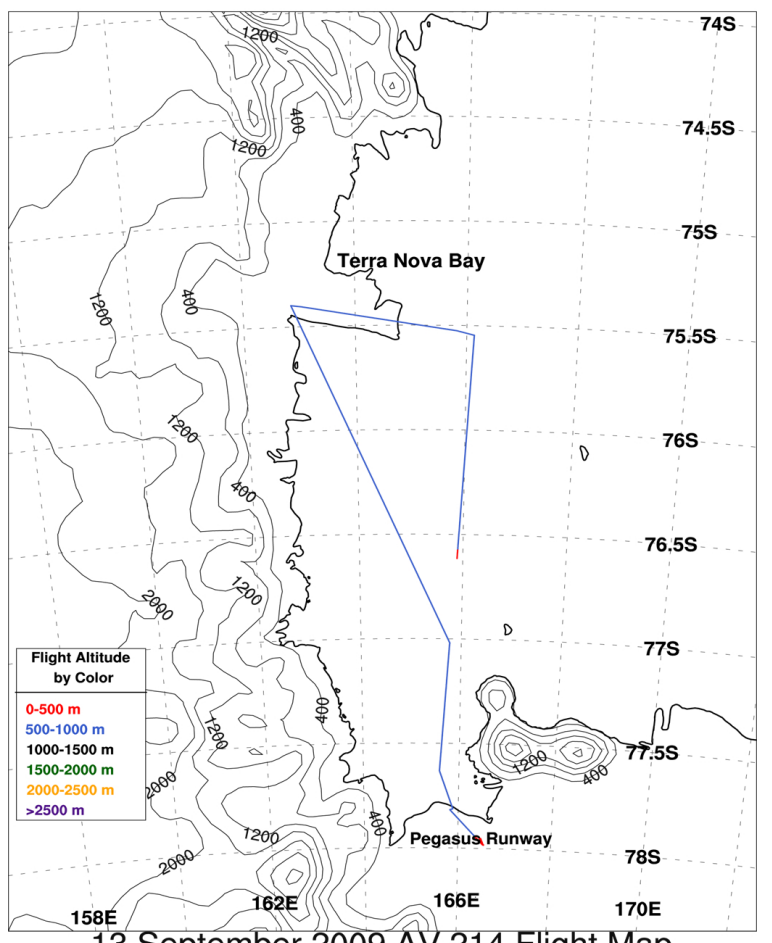

13 September 2009 AV 214 Flight Map

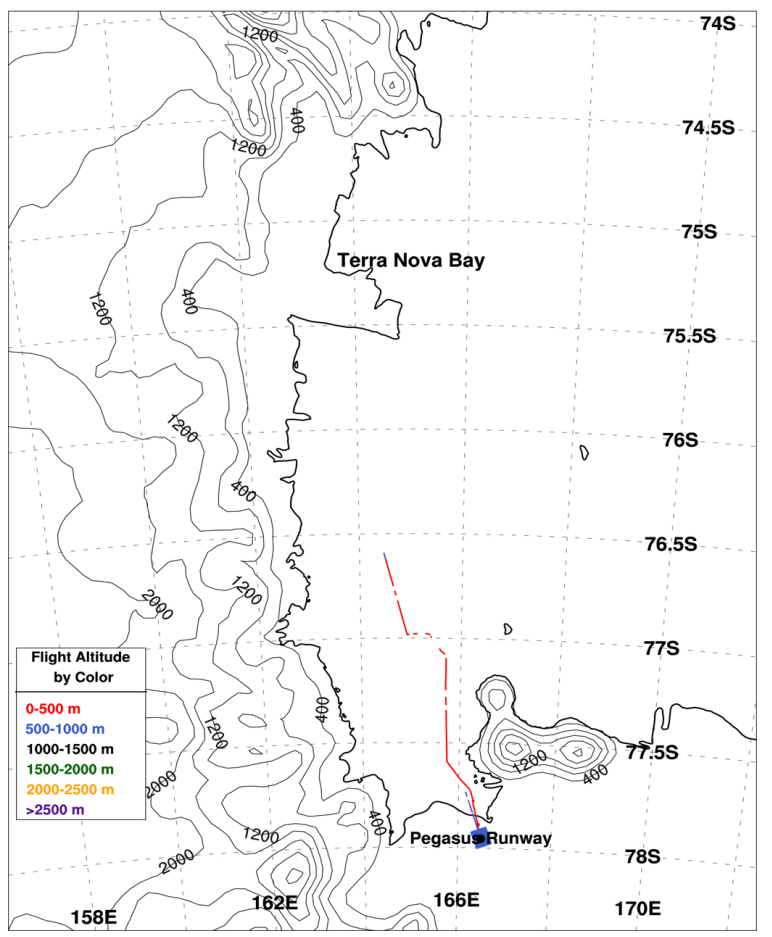

Figure 5. Flight paths for the two flights that did not reach Terra Nova Bay. Gaps in the flight path indicate a lack of data. Profile locations are marked with a black dot. Flight altitude is indicated by the color scale shown in each panel. Topographical contours are in meters. 
Table 1. Start and end times (in UTC) and the UAS aircraft number for science flights to TNB and local flights near Pegasus ice runway.

\begin{tabular}{lclc}
\hline \multicolumn{1}{c}{ Science Flights } & \multicolumn{1}{c}{ Local/Unsuccessful TNB Flights } \\
\hline Start - End Times & UAS Number & Start - End Times & UAS Number \\
\hline Start: 14 Sep 04:37:28 & 214 & Start: 7 Sep 00:14:38 & 217 \\
End: 14 Sep 19:39:45 & & End: 7 Sep 01:04:08 & \\
\hline Start: 18 Sep 03:02:54 & 214 & Start: 8 Sep 21:02:20 & 217 \\
End: 18 Sep 19:39:00 & & End: 9 Sep 03:47:30 & \\
\hline Start: 21 Sep 18:51:54 & 214 & Start: 9 Sep 00:56:57 & 214 \\
End: 22 Sep 05:51:32 & & End: 9 Sep 05:29:31 & \\
\hline Start: 23 Sep 19:09:10 & 215 & Start: 10 Sep 05:58:57 & 214 \\
End: 24 Sep 06:24:48 & & End: 10 Sep 06:26:07 & \\
\hline Start: 23 Sep 20:08:09 & 216 & Start: 12 Sep 04:02:24 & 215 \\
End: 24 Sep 06:13:28 & & End: 12 Sep 04:52:24 & \\
\hline Start: 25 Sep 06:50:11 & 215 & Start: 13 Sep 04:38:49 & 214 \\
End: 25 Sep 19:41:38 & & End: 13 Sep 21:44:35 & \\
\hline Start: 26 Sep 18:33:46 & 214 & Start: 16 Sep 03:20:19 & 215 \\
End: 27 Sep 04:35:04 & & End: 16 Sep 06:30:39 & \\
\hline Start: 26 Sep 19:23:40 & 216 & Start: 22 Sep 04:52:04 & 216 \\
End: 27 Sep 04:19:51 & & End: 22 Sep 06:18:34 & \\
\hline
\end{tabular}
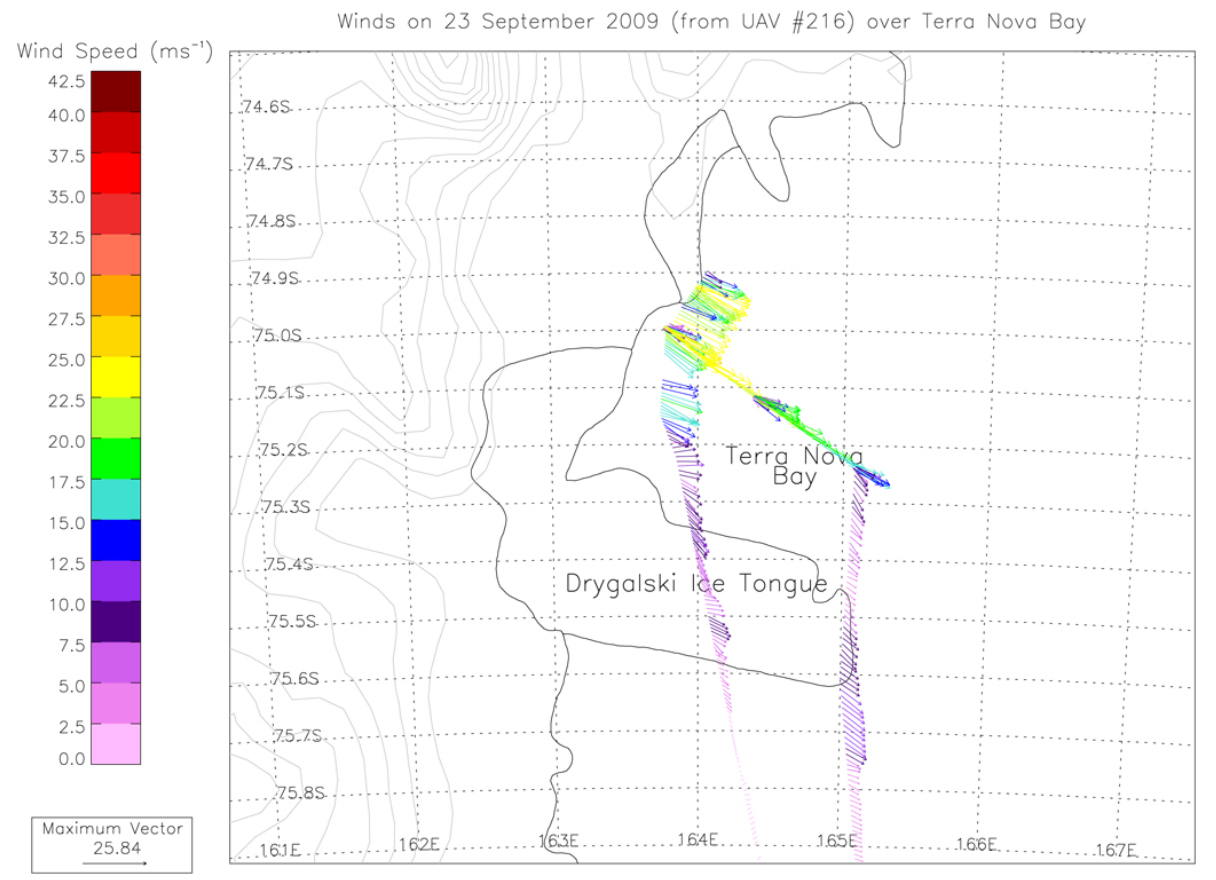

Figure 6. Winds observed during the 23 September 2009 UAS flight over Terra Nova Bay.

during the flight. Periodic "wind finding" maneuvers were performed during the flight to improve the wind estimates which otherwise degrade in accuracy over time whilst flying a constant heading, as the aircraft heading is not directly observable without magnetometer input. It is important to note that the response time of the relative humidity sensor is likely slower than stated due to the cold temperatures in the region and that this may present some issues when interpreting the data collected during the quick ascent/descent of the profiles 


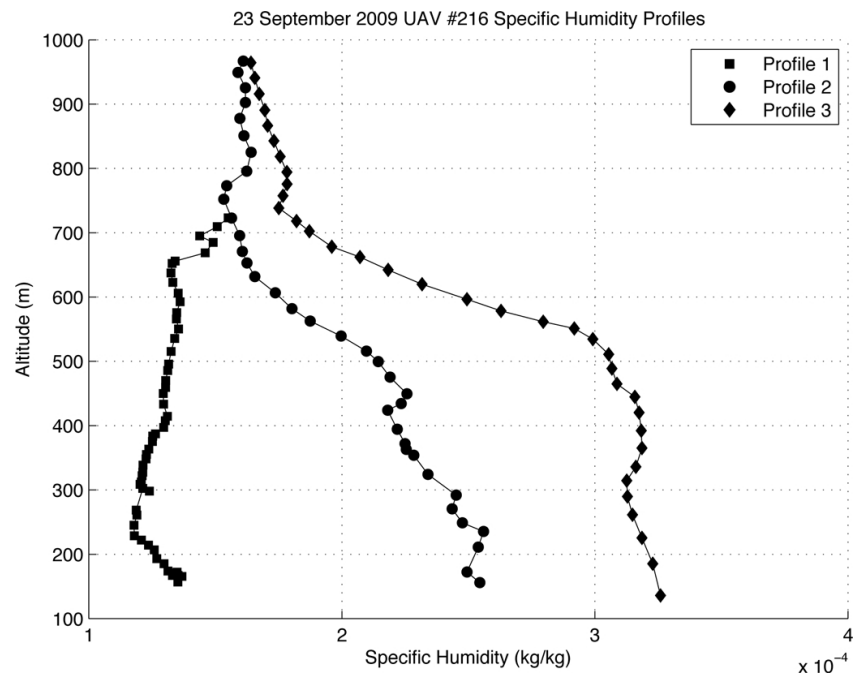

Figure 7. Specific humidity profiles from the 23 September 2009 (UAS \#216) flight. Profile 1 was measured at approximately 01:35 UTC, Profile 2 was measured at approximately 01:52 UTC, and Profile 3 was measured at approximately 02:18 UTC on 24 September 2009.

(Table 2). These data in the soundings should, as such, be used with caution.

One UAS was also outfitted with a Kipp and Zonen CNR2 radiometer to measure shortwave and longwave radiation. An additional GPS, a Canmore GT-730F, was also added to several UASs. Finally, a laser altimeter was used to measure sea ice freeboard and wave state. This laser altimeter, part of the CU LIDAR Profiling and Imaging System (CULPIS), was designed by the University of Colorado (Crocker et al., 2012). The CULPIS profilometer was designed specifically to collect fine-resolution surface elevation measurements from small UASs in polar environments (Crocker et al., 2012). The system consists of a single-beam nearinfrared LiDAR sensor that measures the distance from the aircraft to the ground surface at $400 \mathrm{~Hz}$, a L1 GPS unit that detects the aircraft's altitude and location at $10 \mathrm{~Hz}$, and an inertial measurement unit (IMU) that determines the aircraft's attitude and the LiDAR pointing angle at $100 \mathrm{~Hz}$. Due to payload capacity, however, the altimeter was only present on two flights.

The extreme conditions during the end of the Antarctic winter led to aircraft issues on several flights. Aircraft \#217, flown on 8 September, crashed on the sea ice near $76.62^{\circ} \mathrm{S}$ $165.89^{\circ} \mathrm{E}$ on its return flight to Pegasus Runway. It is suspected that a fuel pump failure caused the engine to fail and the plane to crash. On 10 September, aircraft \#215 indicated a generator belt failure shortly after take off. The Aerosonde ${ }^{\circledR}$ pilots were able to make an emergency landing at Pegasus Runway without incident. On 13 September, aircraft \#214 lost Iridium communications with the ground team at Pegasus Runway. After a half hour of lost communications, the
Table 2. Instrument specifications for the equipment carried on board the UAS.

\begin{tabular}{llll}
\hline Instrument & Accuracy & $\begin{array}{l}\text { Response } \\
\text { Time }\end{array}$ & $\begin{array}{l}\text { Operating } \\
\text { Temperature } \\
\text { Range }\end{array}$ \\
\hline $\begin{array}{l}\text { Piccolo } \\
\text { Autopilot }\end{array}$ & - & - & -40 to $+80^{\circ} \mathrm{C}$ \\
\hline $\begin{array}{l}\text { Vaisala } \\
\text { PTB110 }\end{array}$ & $\begin{array}{l} \pm 1.5 \mathrm{hPa} \\
\left(\text { at }+20^{\circ} \mathrm{C}\right)\end{array}$ & $\begin{array}{l}500 \mathrm{~ms} \\
\left(\text { at }+20^{\circ} \mathrm{C}\right)\end{array}$ & -40 to $+60^{\circ} \mathrm{C}$ \\
\hline $\begin{array}{l}\text { Everest } \\
3800 Z \mathrm{~L}\end{array}$ & $\pm 0.5^{\circ} \mathrm{C}$ & $0.25 \mathrm{~s}$ & -40 to $+100^{\circ} \mathrm{C}$ \\
\hline $\begin{array}{l}\text { Vaisala } \\
\text { HMM213 }\end{array}$ & $\begin{array}{l} \pm-3 \%(\mathrm{RH}), \\
\left(\text { at }+20^{\circ} \mathrm{C}\right)\end{array}$ & $\begin{array}{l}60 \mathrm{~s} \\
\left(\text { at }+20{ }^{\circ} \mathrm{C}\right)\end{array}$ & -70 to $+180^{\circ} \mathrm{C}$ \\
\hline $\begin{array}{l}\text { Kipp and Zonen } \\
\text { CNR2 }\end{array}$ & $10-20 \mu \mathrm{V} \mathrm{W} \mathrm{m}^{-1} \mathrm{~m}^{-2}$ & $<10 \mathrm{~s}$ & -40 to $+80^{\circ} \mathrm{C}$ \\
\hline $\begin{array}{l}\text { Canmore } \\
\text { GT-730F }\end{array}$ & $5 \mathrm{~m}$ & $1 \mathrm{~s}$ & -40 to $+85^{\circ} \mathrm{C}$ \\
\hline CULPIS & $1 \mathrm{~m}$ globally & - & -15 to $50^{\circ} \mathrm{C}$ \\
\hline
\end{tabular}

aircraft returned to Pegasus, where $900-\mathrm{MHz}$ radio communications were reestablished, and flew over the runway for over $12 \mathrm{~h}$ until daylight permitted safe landing by personnel.

A variety of conditions were sampled during the sixteen flights to TNB or near Pegasus Runway. A summary of these conditions (maximum, minimum, and mean temperature, maximum and mean wind speed, mean wind direction, and maximum flight altitude) is listed in Table 3. Figure 8 shows the National Centers for Environmental Prediction/National Center for Atmospheric Research (NCEP/NCAR) reanalysis of mean sea level pressure for the six days on which flights were flown to TNB.

\section{Data description}

There were five data streams in which the data were collected from the UAS - four logger data streams and one telemetered (Table 4). The telemetered data stream was sent back to the field team in real time to monitor the aircraft and the weather (specifically temperature, wind speed and direction, and relative humidity) in which it was flying. The data sent back in real time consisted of latitude, longitude, altitude, ground speed and direction, roll, pitch, and yaw data, air pressure, air temperature, relative humidity, $\mathrm{u}$ - and v-components of the wind, skin temperature, longwave and shortwave radiation, and other data relevant to monitor the aircraft (such as box temperature or instrument voltages). The latitude, longitude, altitude, ground speed and direction, roll, pitch, yaw, air pressure, and $\mathrm{u}$ - and v-components of the wind were sourced from the Piccolo avionics. The remaining data were typically the same as that logged on board the aircraft but telemetered at a different sampling rate (generally lower) than was logged. The one exception is the $\mathrm{u}$ - and v-components of the 
Table 3. Maximum, minimum, and average values for various meteorological variables during each of the sixteen UAS flights. The first column lists the day of September 2009 for the start of each flight and the UAS number.

\begin{tabular}{rlllrrrr}
\hline Date and UAS & \multicolumn{3}{c}{ Temperature $\left({ }^{\circ} \mathrm{C}\right)$} & \multicolumn{2}{c}{ Wind Speed $\left(\mathrm{m} \mathrm{s}^{-1}\right)$} & Wind Direction $\left({ }^{\circ}\right)$ & Altitude $(\mathrm{m})$ \\
\cline { 2 - 8 } number & Max & Min & Mean & Max & Mean & Mean & Max \\
\hline $7, \# 217$ & -19 & -26.4 & -21.48 & 12.82 & 6.63 & 291.33 & 712.17 \\
$8, \# 217$ & -18.6 & -34 & -22.16 & 12.01 & 4.44 & 244.26 & 753.84 \\
$9, \# 214$ & -21.3 & -35.1 & -24.83 & 16.48 & 2.83 & 197.81 & 1355 \\
$10, \# 214$ & -28 & -37 & -28.85 & 8.77 & 3.93 & 176.43 & 587.03 \\
$12, \# 215$ & -13.3 & -26.2 & -14.91 & 18.35 & 6.13 & 223.87 & 577.95 \\
$13, \# 214$ & -4.3 & -29.17 & -10.95 & 14.84 & 4.87 & 210.49 & 654.95 \\
$14, \# 214$ & -12.97 & -34.43 & -19.07 & 28.29 & 8.19 & 176 & 1554.03 \\
$16, \# 215$ & -17.6 & -33.1 & -25.15 & 12.61 & 5.07 & 137.43 & 3054.16 \\
$18, \# 214$ & -15.94 & -28.54 & -20.86 & 25.65 & 10.39 & 202.7 & 1567.35 \\
$21, \# 214$ & -21.38 & -29.76 & -24.31 & 24.98 & 7.81 & 200.85 & 1560.43 \\
$22, \# 216$ & -24.36 & -27.74 & -26.27 & 9.19 & 4.65 & 85.84 & 985.12 \\
$23, \# 215$ & -21 & -35.35 & -24.23 & 26.56 & 6.63 & 266.03 & 2557.18 \\
$23, \# 216$ & -21.37 & -36.62 & -23.96 & 25.98 & 6.38 & 267.91 & 1559.15 \\
$25, \# 215$ & -15.53 & -33.38 & -19.08 & 27.97 & 6.06 & 232.08 & 2056.87 \\
$26, \# 214$ & -17.39 & -34.28 & -23.24 & 34.84 & 10.1 & 231.03 & 1833.5 \\
$26, \# 216$ & -17.7 & -34.2 & -23.79 & 39.89 & 8.85 & 214.5 & 2567.25 \\
\hline
\end{tabular}

wind, which were only telemetered and not logged by the on-board data logger.

The final four data streams were from various logger systems on the UAS, with the first of these from the Canmore GPS. The data within this stream consisted of latitude, longitude, altitude, and ground speed, and were only available on certain flights (Table 5). The second data stream was the logged analog-to-digital converter (ADC) data that consisted of longwave and shortwave radiation, static air pressure, and skin temperature. The third logged data stream was from the RS232 logger interface consisting of temperature and relative humidity data. The final data stream consisted of the laser altimeter data from the CULPIS instrument. Surface elevation measurements were derived from the LiDAR range data, the GPS position data, and the IMU pointing data during post-processing, although these data have not undergone full post-processing.

The data logged on board and telemetered to the field team were collected at varying sampling rates. The telemetered data were sent back at a sampling rate of $1 \mathrm{~Hz}$ when within line of site using the $900-\mathrm{MHz}$ radio link, and at $0.33 \mathrm{~Hz}$ when using Iridium connectivity. The logged data from the RS232 were collected at a rate of $0.10 \mathrm{~Hz}$, while the ADC logged data were collected at $10 \mathrm{~Hz}$. The GPS data were logged at a rate of $1 \mathrm{~Hz}$. When the data in the logger file are at a lower sampling rate than the rate at which the telemetered data are provided, the data in the telemetered file are repeated. When the data in the logger file are at a higher sampling rate than the telemetered data, not all of the logger data are included in the telemetered file.

Data were logged and telemetered during pre-flight operations as well as the actual flight of the aircraft. Using the ground speed and altitude data to determine when the UAS was airborne, the five data streams were concatenated to only include data during the actual flight time.

\section{Quality control}

Quality control (QC) was performed on the data in four of the five data streams as well as synced for similar sampling rates. Spurious data points, unit changes, and other corrections needed to be made in each dataset. The CULPIS data provided are the raw LIDAR, GPS, and IMU measurements, and post-processing and QC have not been performed on these data. A summary of the $\mathrm{QC}$ process for all other data is provided below.

\subsection{RS232 data (temperature and relative humidity)}

The data within the RS232 data stream were not time stamped when logged, and extra processing was needed to ensure proper accuracy when adding time markers to these data. To accomplish this, the RS232 logged data were compared to the telemetered temperature and relative humidity to determine a matching point between the two files. Because the RS232 logger had a step counter, once an initial matching point was determined, subsequent time markers could be added. This application of time markers could yield an inaccuracy of up to $1-2 \mathrm{~s}$. This is because the telemetered data are occasionally repeated, and when searching for the initial time marker, it can be difficult to determine which value in the telemetered file is the true initial start time. 

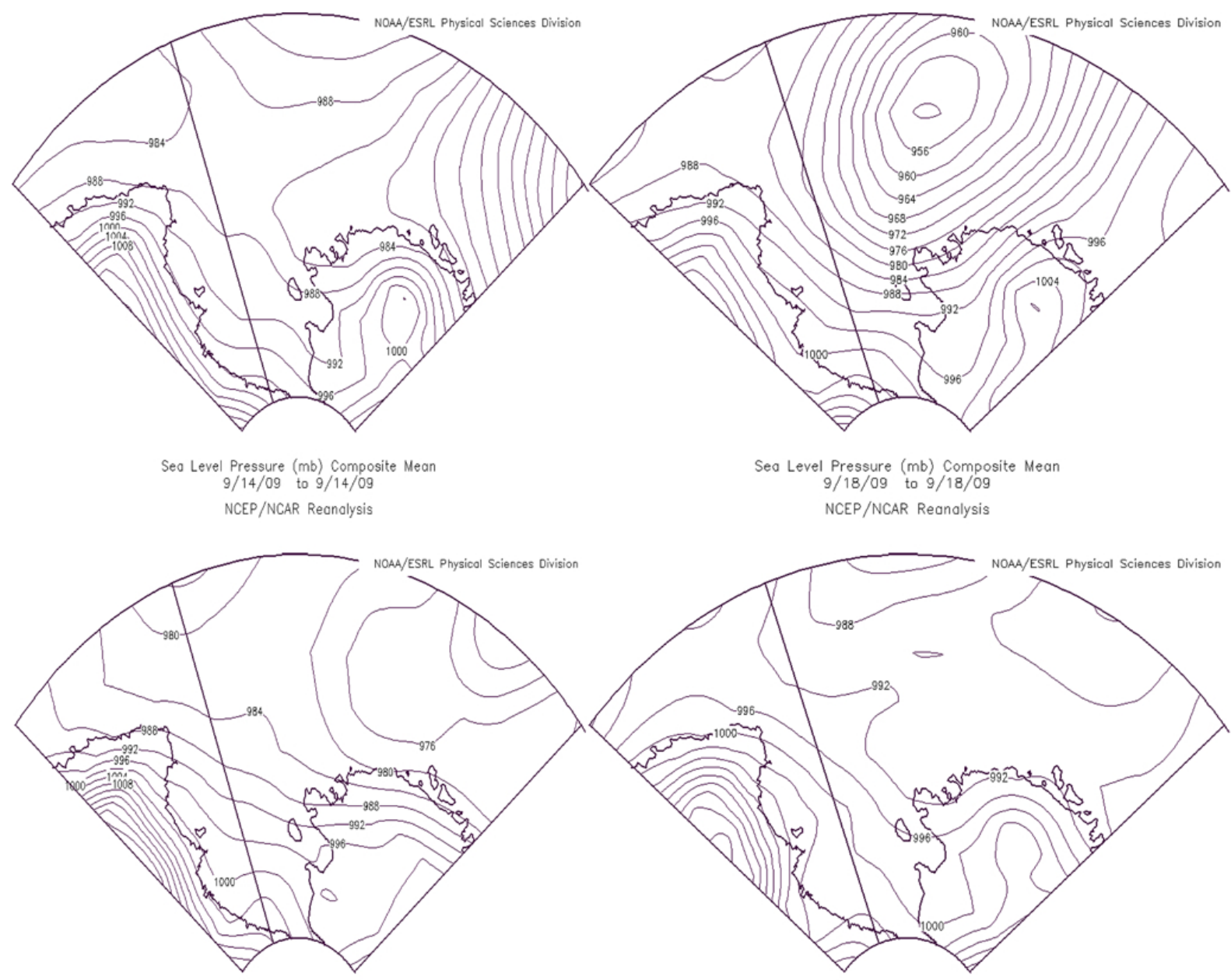

Sea Level Pressure (mb) Composite Mean
$9 / 18 / 09$ to $9 / 18 / 09$
NCEP/NCAR Reanalysis

Seo Level Pressure (mb) Composite Mean
$9 / 21 / 09$ to $9 / 21 / 09$

NCEP/NCAR Reonolysis
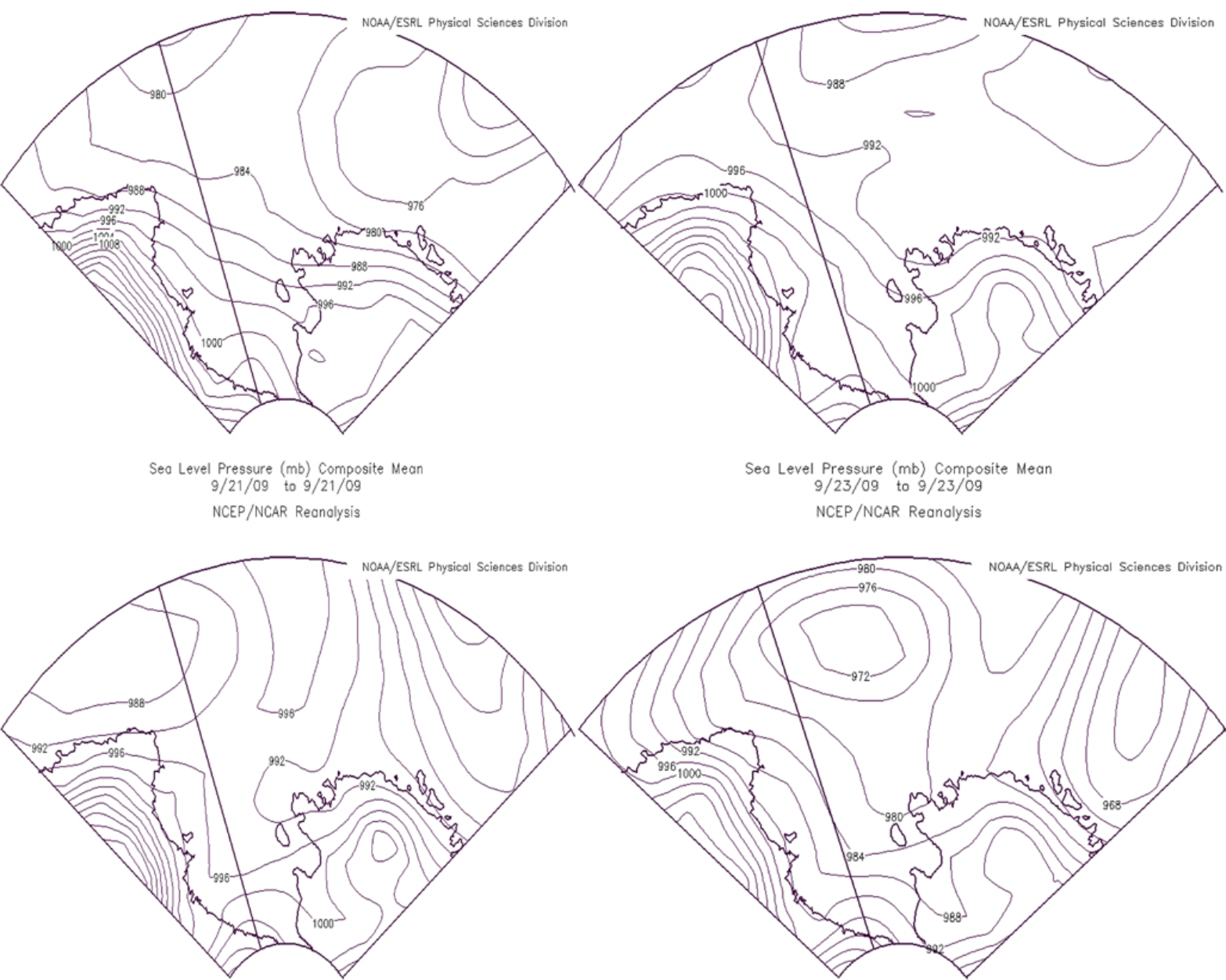
Seo Level Pressure (mb) Composite Mean $9 / 25 / 09$ to $9 / 25 / 09$ NCEP/NCAR Reonolysis

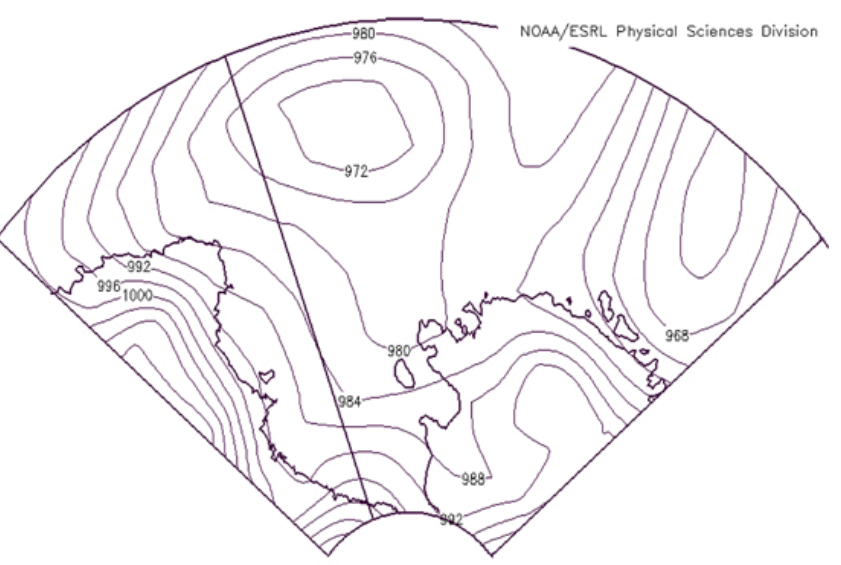

Sea Level Pressure (mb) Composite Mean $9 / 26 / 09$ to $9 / 26 / 09$ NCEP/NCAR Reanalysis

Figure 8. NCEP/NCAR reanalysis of mean sea level pressure data for the days on which flights were flown to TNB. Image provided by the NOAA/ESRL Physical Sciences Division, Boulder, Colorado, from their website at http://www.esrl.noaa.gov/psd/ (Kalnay et al., 1996). 
Table 4. Data available in the four logger and one telemetered data streams. Sampling rates are also given.

\begin{tabular}{lll}
\hline Data Stream & \multicolumn{2}{c}{ Measurements } \\
& Latitude & Air Temperature \\
& Longitude & Air Pressure \\
& Altitude & Relative Humidity \\
& Ground Speed & $\begin{array}{l}\text { Longwave Radiation } \\
\text { Shortwave Radiation } \\
\text { Telemetered }(0.33-1 \mathrm{~Hz})\end{array}$ \\
& Ground Direction & Skin Temperature \\
& Poll & u-Component of Wind \\
& Yaw & v-Component of Wind \\
\hline \multirow{2}{*}{ GPS $(1 \mathrm{~Hz})$} & Latitude & $\begin{array}{l}\text { Altitude } \\
\text { Ground Speed }\end{array}$ \\
\hline \multirow{2}{*}{ ADC $(10 \mathrm{~Hz})$} & Longitude & $\begin{array}{l}\text { Air Pressure } \\
\text { RS232 }(0.10 \mathrm{~Hz})\end{array}$ \\
\hline CULPIS & Longwave Radiation Temperature \\
\hline
\end{tabular}

\subsection{ADC data (air pressure, longwave and shortwave radiation, and skin temperature)}

The data within the ADC logger file were also not time stamped, but also did have a step counter. However, there were no common data values between the telemetered and ADC logger data to set an initial time stamp, as was true with the RS232 data. In order to set an appropriate time stamp to the ADC logged data, a manual record of when the ADC logger was switched on was used to time stamp the initial value reported in the ADC logged data stream.

The unavailability of comparable data within the two data streams existed for several reasons. Firstly, when the skin temperature and longwave and shortwave radiation voltages from their respective instruments were reported through the telemetered and logger process, the data were compared to two different reference values and calibrated, and thus the final reported value was slightly different for each. Secondly, there were two types of pressure data - the air pressure provided by the Piccolo avionics package and the air pressure provided from the Vaisala meteorological sensor. Both values were telemetered, but the Vaisala pressure that was telemetered needed to undergo a conversion process, and thus a direct comparison between the two could not be made.

The Everest skin temperature was also calibrated and corrected via post-processing steps due to issues discovered during flight operations. It was determined that when the infrared probe was in a cold environment and sensing a relatively warmer environment (such as when flying above open ocean) the thermometer would report an incorrect value (i.e., instrument housing temperature affected the estimated radiometric temperature). This problem was identified through ground calibration tests done on site. The post-processing corrections were carried out by determining the sensor readings that corresponded to a known low-temperature target and a high-temperature target. The high-temperature target
Table 5. Available data for each of the sixteen September 2009 flights.

\begin{tabular}{|c|c|c|c|c|}
\hline $\begin{array}{r}\text { Date and UAS } \\
\text { number }\end{array}$ & RS232 & GPS & $\mathrm{ADC}$ & Telemetered \\
\hline 7 Sep, \#217 & & & & $\mathrm{X}$ \\
\hline 8 Sep, \#217 & & & & $X$ \\
\hline 9 Sep, \#214 & & & $\mathrm{X}$ & $X$ \\
\hline 10 Sep, \#214 & & & & $\mathrm{X}$ \\
\hline 12 Sep, \#215 & & & & $X$ \\
\hline 13 Sep, \#214 & $X$ & & & $X$ \\
\hline 14 Sep, \#214 & $X$ & $X$ & $X$ & $X$ \\
\hline 16 Sep, \#215 & & & & $X$ \\
\hline 18 Sep, \#214 & $X$ & $X$ & $X$ & $X$ \\
\hline 21 Sep, \#214 & $\mathrm{X}$ & $X$ & $\mathrm{X}$ & $\mathrm{X}$ \\
\hline 22 Sep, \#216 & $\mathrm{X}$ & $X$ & $X$ & $X$ \\
\hline 23 Sep, \#215 & $\mathrm{X}$ & & $\mathrm{X}$ & $\mathrm{X}$ \\
\hline 23 Sep, \#216 & $\mathrm{X}$ & $\mathrm{X}$ & $\mathrm{X}$ & $\mathrm{X}$ \\
\hline 25 Sep, \#215 & $X$ & & $X$ & $X$ \\
\hline 26 Sep, \#214 & $X$ & $X$ & $X$ & $X$ \\
\hline 26 Sep, \#216 & & $X$ & $X$ & $X$ \\
\hline
\end{tabular}

was represented by open water areas during flight, as determined using the Canon aerial photographs. These were assumed to be at a sea-water freezing point of $-1.8^{\circ} \mathrm{C}$. Lowtemperature tie-points were determined by comparing the Everest readings to cold land ice, with temperatures given by near-coincident MODIS satellite data. A linear fit between voltages associated with the low- and high-temperature targets was then used to convert all voltages to temperatures. This process was done for each flight individually. The estimated error associated with this ad hoc calibration is about 2 degrees.

Longwave and shortwave radiation data were only available on the flights on 23 September (\#216) and 26 September (\#216). These data have not been quality controlled or corrected for aircraft orientation. It is suggested that users carefully evaluate these data prior to use.

\subsection{GPS data (latitude, longitude, altitude, ground speed)}

The Canmore GPS altitude data were reported as height above the WGS84 ellipsoid rather than altitude above the surface. Consequently, the ellipsoid height needed to be converted to topographic altitude by correcting with the EGM96 datum geoid height, which was found at each latitude and longitude location along the flight path. This correction does not provide the exact height above the surface due to the variable influence of ocean dynamic topography, tides, and atmospheric pressure loading, but it does provide the aircraft mean sea level (MSL) altitude. 
Table 6. A sample of the data available in the USAP-DCC repository. Data have been truncated in this table to save space.

\begin{tabular}{rccrcccccccc}
\hline Day & Hour & Minute & Second & $\begin{array}{c}\text { Latitude } \\
(\mathrm{deg})\end{array}$ & $\begin{array}{l}\text { Longitude } \\
(\mathrm{deg})\end{array}$ & $\begin{array}{r}\text { Altitude } \\
(\mathrm{m})\end{array}$ & $\begin{array}{l}\text { Temp } \\
(\mathrm{C})\end{array}$ & $\begin{array}{r}\text { RH } \\
(\%)\end{array}$ & $\begin{array}{r}\text { Pressure } \\
(\mathrm{Pa})\end{array}$ & $\begin{array}{l}\text { Wind Speed } \\
\left(\mathrm{m} \mathrm{s}^{-1}\right)\end{array}$ & $\begin{array}{l}\text { Wind Direction } \\
(\mathrm{deg})\end{array}$ \\
\hline 23 & 20 & 8 & 9.54 & -77.95 & 166.49 & 4.71 & -33.89 & 70.67 & 100378.09 & 0 & 0 \\
23 & 20 & 8 & 29.54 & -77.95 & 166.5 & 3.55 & -36.31 & 70.67 & 100255.65 & 7.62 & 0 \\
23 & 20 & 8 & 39.54 & -77.96 & 166.5 & 33.88 & -30.6 & 73.05 & 99866.85 & 1.94 & 231.5 \\
\hline
\end{tabular}

\subsection{Telemetered data}

Very little processing was required of the telemetered data. The altitude reported as part of the Piccolo system was also the ellipsoid height, and it also needed to be corrected by the geoid height to obtain the true altitude above mean sea level. As well, the $\mathrm{u}$ - and $\mathrm{v}$-components of the wind provided from the Piccolo were converted into wind speed and direction. The telemetered data were repeated at times such that several different time stamps might have the same data over a given time span. In these cases, the first repeated data and time stamp were kept.

Additionally, there are a few instances where one time stamp might report two different values of data - for example, a single time stamp might have two different temperature values. These seemingly repeating time data are actually not repeating data at all, but rather an issue that occurred when the data were telemetered back in real time. Sometimes there would be delays in the transmission of telemetered data that would cause several data packets to be sent at once. Typically when there are repeating data, there is a data gap that occurs adjacent to the data. However, because the correct time of the repeated data cannot be accurately determined, the data in the file have been left as is.

\section{Data availability}

The data from the September 2009 Antarctica flights have been submitted to the United States Antarctic Program Data Coordination Center (USAP-DCC) (doi:10.1594/USAP/0739464). The available data are in text and csv formats and are provided at ten-second intervals, representing the lowest sampling rate of the logged data, with an accuracy to within five seconds (Table 6). The data from the flights provided in these files are: date and time, latitude, longitude, altitude, temperature, relative humidity, pressure, wind speed, wind direction, $\mathrm{u}$ - and v-components of the wind, longwave and shortwave radiation, skin temperature, ground speed and direction, roll, pitch, and yaw, and laser altimeter.

As described in Sect. 3, there are several instruments that might provide duplicate data (for example, on flights when the Piccolo and Canmore GPS are used). As such, there is a hierarchy to the type of data provided in the final dataset. Typically, data provided by instruments that are not part of the Piccolo system, and were added specifically as part of the 2009 flights, are used whenever available. This impacts latitude, longitude, altitude, pressure, and ground speed data. If the Canmore GPS data are available, the latitude, longitude, and altitude from that device will be used over the Piccolo GPS data. The only exception to this is the ground speed data. Because the Canmore GPS did not provide ground direction data, the ground speed and direction data reported are always from the Piccolo system.

Because the Piccolo air pressure was not used during flight operations and therefore was not properly calibrated, the Vaisala air pressure was used whenever available. In instances where the Piccolo air pressure needed to be used, the data were rigorously analyzed to ensure validity. The air pressure at flight take-off and landing was compared to a local automatic weather station at the Pegasus ice runway to determine both accuracy and that any differences between the two pressures at take-off were the same when the aircraft landed. For all flights where the Piccolo air pressure was used, it was deemed to be accurate.

\section{Summary}

In September 2009, a series of long-range unmanned aircraft system flights were made to Terra Nova Bay, Antarctica, to study the downstream evolution of the atmospheric boundary layer over a latent heat polynya during winter conditions. Eight flights were flown on science missions to Terra Nova Bay, with an additional six flights flown near the Pegasus ice runway (the origin of the UAS flights) as test flights to ensure proper aircraft operations. Two additional flights were attempted to TNB, but were unsuccessful. The data were quality controlled and processed, and have been submitted to the USAP-DCC data repository for public use. The data available at the USAP-DCC consist of date and time, latitude, longitude, altitude, temperature, relative humidity, pressure, wind speed, wind direction, u- and v-components of the wind, longwave and shortwave radiation, skin temperature, ground speed and direction, and roll, pitch, and yaw provided at ten-second intervals for all sixteen flights. The laser altimeter data for two of the flights are also provided.

Acknowledgements. The authors wish to thank Michael Willis of Cornell University and Seth White of UNAVCO for their assistance with the technical aspects of understanding geoid and ellipsoid heights. Automatic weather station data from the 
Antarctic Meteorological Research Center at the University of Wisconsin-Madison were used to analyze the Piccolo air pressure. This work was supported by NSF grant ANT 0739464.

Edited by: G. König-Langlo

\section{References}

Cassano, J. J., Maslanik, J. A., Zappa, C. J., Gordon, A. L., Cullather, R. I., and Knuth, S. L.: Observations of Antarctic Polynya With Unmanned Aircraft Systems, EOS, 91, 245-246, doi:10.1029/2010EO280001, 2010.

Ciappa, A., Pietranera, L., and Budillon, G.: Observations of the Terra Nova Bay (Antarctica) polynya by MODIS ice surface temperature imagery from 2005 to 2010, Remote Sens. Environ., 119, 158-172, 2012.

Crocker, R. I., Maslanik, J. A., Adler, J. J., Palo, S. E., Herzfeld, U. C., and Emery, W. J.: A sensor package for ice surface observations using small unmanned aircraft systems, IEEE T. Geosci. Remote Sens., 50, 1033-1047, 2012.
Curry, J. A., Maslanik, J. A., Holland, G., Pinto, J., Tyrrell, G., and Inoue, J.: Applications of Aerosondes in the Arctic, B. Am. Meteorol. Soc., 85, 1855-1861, 2004.

Inoue, J. and Curry, J. A.: Application of Aerosondes to high-resolution observations of sea surface temperature over Barrow Canyon, Geophys. Res. Lett., 31, L14312, doi:10.1029/2004GL020336, 2004.

Inoue, J., Curry, J. A., and Maslanik, J. A.: Application of Aerosondes to melt-pond observations over Arctic sea ice, J. Atmos. Ocean. Tech., 25, 327-334, 2008.

Kalnay, E. and Coauthors: The NCEP/NCAR Reanalysis 40-year Project, B. Am. Meteorol. Soc., 77, 437-471, 1996.

Kurtz, D. D. and Bromwich, D. H.: Satellite observed behavior of the Terra Nova Bay polynya, J. Geophys. Res., 88, 9717-9722, 1993.

Maslanik, J. A., Curry, J., Drobot, S., and Holland, G.: Observations of sea ice using a low-cost unpiloted aerial vehicle, Proc. 16th. IAHR International Symposium on Sea Ice, Int. Assoc. of Hydraulic Engineering and Research, 3, 283-287, 2002. 